\title{
Resposta de Plantas daninhas ao Óleo fúsel Aplicado em Pós-EMERgêncIa INICIAL E TARDIA ${ }^{1}$
}

\author{
Weed Response on Fusel Oil Applied at Initial and Late Post-Emergence
}

AZANIA, C.A.M. ${ }^{2}$, AZANIA, A.A.P.M. ${ }^{3}$, PIZZO, I.V. ${ }^{4}$ e SCHIAVETTO, A.R. ${ }^{4}$

\begin{abstract}
RESUMO - Objetivou-se com este trabalho estudar a resposta de plantas daninhas a doses do óleo fúsel aplicadas em pós-emergência inicial e tardia. Para isso, foram estudadas as espécies Ipomoea hederifolia, Ipomoea quamoclit, Euphorbia heterophylla, Digitaria spp., Cenchrus echinatus e Panicum maximum em pós-emergência inicial e tardia, utilizando-se o delineamento inteiramente casualizado com seis tratamentos, em quatro repetições. O óleo fúsel subproduto da destilação do álcool - foi aplicado nas doses de 50, 125, 250, 375 e $500 \mathrm{~L} \mathrm{ha}^{-1}$, mais a testemunha sem aplicação. As parcelas foram constituídas por vasos de polietileno com capacidade de $3 \mathrm{~L}$, contendo terra da camada arável de uma área em pousio. Avaliou-se o percentual de intoxicação visual aos 7 e 30 dias após aplicação (DAA) e a massa seca aos 30 DAA. As variáveis foram submetidas à análise de variância conforme delineamento, ajustando-se os dados para obtenção da curva dose-resposta por regressão polinomial. As espécies estudadas foram suscetiveis apenas com a utilização de $500 \mathrm{~L} \mathrm{ha}^{-1}$ de óleo fúsel aplicado na pós-emergência inicial ou tardia das plantas. A espécie Digitaria spp. foi suscetivel; $E$. heterophylla, tolerante; e as demais, moderadamente tolerantes ao óleo fúsel aplicado em pós-emergência inicial. A espécie E. heterophylla foi suscetivel; Digitaria spp., C. echinatus e P. maximum, moderadamente tolerante e I. hederifolia e I. quamoclit, tolerantes ao óleo fúsel aplicado em pós-emergência tardia.
\end{abstract}

Palavras-chave: herbicida, seletividade, subproduto.

\begin{abstract}
This work aimed to study weed response to fusel oil rate applied at early and late post-emergence. The following species were studied at late and early post-emergence: Ipomoea hederifolia, Ipomoea quamoclit, Euphorbia heterophylla, Digitaria spp., Cenchrus echinatus and Panicum maximum. The experiment was arranged in a completely randomized design with six treatments and four replications. Fusel oil, an alcohol distillation byproduct, was applied at rates of 50, 125, 250, 375 and $500 \mathrm{~L} \mathrm{ha}^{-1}$, plus control without application. The plots were constituted by polyethylene containers with $3 \mathrm{~L}$ capacity, filled with topsoil land from a fallow area. Visual symptoms of intoxication were verified at 7 and 30 days after application (DAA) and dry weight at 30 DAA. The variables were submitted to variance analysis according to the design, adjusting the data to obtain the dose-response curve by polynomial regression. The studied species were susceptible only to the application of $500 \mathrm{~L} \mathrm{ha}^{-1}$ of fusel oil at early or late plant postemergence. The species Digitaria spp. was susceptible and $\boldsymbol{E}$. heterophylla tolerant to fusel oil applied at early post-emergence, while the other species were moderately tolerant. $\boldsymbol{E}$. heterophylla was susceptible, Digitaria spp., C. echinatus and $\boldsymbol{P}$. maximum moderately tolerant and I. hederifolia and I. quamoclit tolerant to fusel oil applied at late post-emergence.
\end{abstract}

Keywords: herbicide, selectivity, by-product.

1 Recebido para publicação em 28.9.2009 e na forma revisada em 3.9.2010.

2 Engo-Agr ${ }_{-}^{-}$, Dr., PqC Instituto Agronômico - Centro de Cana, Rodov. Pref. Antonio Duarte Nogueira, km 321, $14032-800$ Ribeirão Preto-SP, <azania@iac.sp.gov.br>; ${ }^{2}$ Bióloga, Dra., PqC Voluntária do Instituto Agronômico, Centro de Cana, <andrea.azania@hotmail.com>; ${ }^{3}$ Graduando em Engenharia Agronômica, Centro Universitário Moura Lacerda, Av. Dr. Oscar de Moura Lacerda, 1520, 14076-510 Ribeirão Preto-SP, <igorpizzo@hotmail.com>; ${ }^{4}$ Eng $^{\mathrm{a}}-$ Agr ${ }^{\mathrm{a}}$., mestranda em Genética e Melhoramento de Plantas-FCAVJ/UNESP, Via deAcesso Prof. Paulo Donato Castellane s/n, 14884-900 Jaboticabal-SP, <anaschiavetto@bol.com.br>.

Planta Daninha, Viçosa-MG, v. 28, n. 3, p. 541-549, 2010 


\section{INTRODUÇÃO}

O óleo fúsel é um resíduo gerado na coluna de retificação do processo de obtenção do álcool pelas usinas sucroalcooleiras e explorado por indústrias químicas, que o utilizam como fonte de matéria-prima, principalmente, quanto à extração do álcool isoamílico, que por sua vez é utilizado também na extração de compostos farmacológicos. O volume produzido de óleo fúsel corresponde anualmente a 25 milhões de litros, o que representa $0,3 \%$ da produção total de álcool (Oliveira, 2007). Entre as unidades produtoras, as concentrações dos álcoois constituintes do óleo fúsel variam, mas os álcoois isoamílico, etílico e isobutílico sempre se apresentam em maior quantidade (Perez et al., 2001).

Os trabalhos que visam ao aproveitamento do óleo fúsel na agricultura são recentes na literatura e consistem basicamente no estudo das doses do produto, aplicado com o objetivo de controlar plantas daninhas. Inicialmente, o uso como herbicida foi relatado por Azania et al. (2003), ao observarem reduções na viabilidade de sementes de Sida rhombifolia e inviabilização de Brachiaria decumbens. Em outro estudo, esses autores observaram a inibição da emergência dessas espécies, que são consideradas plantas daninhas importantes na cultura da cana-de-açúcar (Azania et al., 2004).

Em associação com glifosato, o óleo fúsel possibilitou redução da dose do herbicida, com controle máximo sobre uma comunidade natural de plantas daninhas constituídas por Amaranthus spp., Brachiaria spp. e Cenchrus echinatus, mas não controlou as espécies dos gêneros Commelina e Cyperus (Azania et al., 2008). No entanto, Osipe et al. (2009) comprovaram a eficácia do óleo fúsel para o manejo de plantas daninhas no sistema de plantio direto, pois obtiveram resultados satisfatórios no controle de Digitaria insularis e Commelina benghalensis.

Em associação com glifosato, o óleo fúsel possibilitou redução da dose do herbicida, com controle máximo sobre uma comunidade natural de plantas daninhas constituídas por Amaranthus spp., Brachiaria spp. e Cenchrus echinatus, mas não controlou as espécies dos gêneros Commelina e Cyperus (Azania et al., 2008). No entanto, Osipe et al. (2009) compro- varam a eficácia do óleo fúsel para o manejo de plantas daninhas no sistema de plantio direto, pois obtiveram resultados satisfatórios no controle de Digitaria insularis e Commelina benghalensis. Em estudo atual, Pizzo et al. (2010) verificaram que os herbicidas diuron+ hexazinone, metribuzin e amicarbazone quando associados ao óleo fúsel apresentaram controle satisfatório para Panicum maximum, Amaranthus deflexus e Brachiaria decumbens, não controlando apenas Ipomoea quamoclit e Euphorbia heterophylla.

Nesse sentido, torna-se interessante pesquisar a potencialidade agronômica do uso do óleo fúsel na agricultura, por se tratar de um subproduto cujo efeito no solo e nas culturas ainda não é perfeitamente conhecido. Assim, objetivou-se com este trabalho estudar a resposta de espécies de plantas daninhas à aplicação em pós-emergência inicial e tardia de diferentes doses do óleo fúsel.

\section{MATERIAL E MÉTODOS}

Os experimentos com aplicação em pósemergência inicial e tardia das espécies de plantas daninhas foram conduzidos no município de Ribeirão Preto-SP. Para cada época de aplicação foram estudadas as espécies Ipomoea hederifolia, Ipomoea quamoclit, Euphorbia heterophylla, Digitaria spp., Cenchrus echinatus e Panicum maximum, utilizando-se o delineamento inteiramente casualizado com seis tratamentos, em quatro repetições, constituídas pela ausência e $50,125,250,375$ e $500 \mathrm{~L} \mathrm{ha}^{-1}$ do óleo fúsel.

As parcelas foram constituídas por vasos de polietileno com capacidade de $3 \mathrm{~L}$, preenchidos com terra de textura argilosa, previamente peneirada, oriunda da camada arável de uma área não cultivada, cujas características químicas e físicas encontram-se na Tabela 1.

As sementes foram adquiridas em empresa especializada, sendo 200 de cada espécie submetidas ao teste de viabilidade do lote. Estas foram cortadas longitudinalmente, acondicionadas em vidros âmbar, submetidas a solução $0,1 \%$ de cloreto de 2,3,5-trifeniltetrazólio durante oito horas; contou-se o número de sementes com embrião colorido de rosa, caracterizando-se como sementes viáveis. No 
Tabela 1 - Atributos químicos e físicos da terra utilizada no preenchimento dos recipientes

\begin{tabular}{|c|c|c|c|c|c|c|c|c|c|c|c|}
\hline Argila & Areia & Silte & $\mathrm{pH}$ & M.O. & P res. & $\mathrm{K}^{+}$ & $\mathrm{Ca}^{+2}$ & $\mathrm{Mg}^{+2}$ & $\mathrm{SB}$ & $\mathrm{V}$ \\
\hline \multicolumn{3}{|c|}{$(\%)$} & & $\left(\mathrm{CaCl}_{2}\right)$ & $\left(\mathrm{g} \mathrm{dm}^{-3}\right)$ & $\left(\mathrm{mg} \mathrm{dm}^{-3}\right)$ & \multicolumn{3}{|c|}{$\left(\mathrm{mmol}_{\mathrm{c}} \mathrm{dm}^{-3}\right)$} & $(\%)$ \\
\hline 46,6 & 16,1 & 37,3 & 5,6 & 24 & 38 & 3,4 & 54 & 24 & 81,0 & 69,3 \\
\hline
\end{tabular}

Análise realizada no DMLab. Ribeirão Preto-SP.

final desse procedimento observaram-se 98\% de viabilidade para todas as espécies.

O óleo fúsel utilizado apresentava, de acordo com os resultados da análise por cromatografia gasosa, metanol $(1,70 \% \mathrm{v} / \mathrm{v})$, etanol $(19,5 \% \mathrm{v} / \mathrm{v})$, n-propanol (0,97\% v/v) e álcool isoamílico $(67,3 \% \mathrm{v} / \mathrm{v})$ em sua constituição. As doses do óleo fúsel utilizadas foram escolhidas com base em resultados observados em literatura (Azania et al., 2004, 2008).

Foram semeadas 25 sementes de cada espécie por parcela em 4/1/2008 e não se realizou desbaste no experimento em pósemergência inicial, mas no experimento em pós-emergência tardia deixaram-se apenas três plantas em cada parcela; na sequência, procedeu-se à aplicação do óleo fúsel em pós-emergência inicial (1/2/2008) e tardia (29/3/2008). No momento anterior às aplicações, as plantas daninhas foram caracterizadas quanto à altura $(\mathrm{cm})$, medindo-se cinco plantas escolhidas ao acaso na condição de pós-emergência inicial e três plantas na condição de pós-emergência tardia, caracterizando (em $\mathrm{cm})$ : Ipomoea hederifolia $(5,2$ e 33,3), Ipomoea quamoclit (4,9 e 44,7), Euphorbia heterophylla (4,8 e 20,0), Digitaria spp. (0,5 e 13,4), Cenchrus echinatus $(3,7$ e 5,7) e Panicum maximum $(2,3$ e $7,2)$, respectivamente para pós-emergência inicial e tardia.

As aplicações foram realizadas utilizandose equipamento costal pressurizado a $\mathrm{CO}_{2}$, munido de barra com quatro pontas TT 11004 , regulado à pressão de 40 Psi, o que proporcionou volume de calda de $500 \mathrm{~L} \mathrm{ha}^{-1}$. No momento das aplicações, respectivamente para pós-emergência inicial e tardia, registraramse temperatura do ar $\left(30,8\right.$ e $\left.31^{\circ} \mathrm{C}\right)$, umidade relativa do ar (53 e 45,2\%), ventos em rajadas $\left(3,6\right.$ e $\left.3,5 \mathrm{~km} \mathrm{~h}^{1}\right)$ e nebulosidade (10 e $\left.5 \%\right)$.

Foram avaliados os sintomas de intoxicação visual nas plantas (injúrias) aos $7 \mathrm{e}$
30 dias após aplicação (DAA). As avaliações constaram de notas percentuais e visuais variando de 0 a $100 \%$, em que $0 \%$ corresponde à ausência de injúrias e $100 \%$ à morte das plantas. Avaliou-se também a massa seca aos 30 DAA, cortando-se as plantas rente ao solo, com posterior secagem em estufa de circulação forçada a $70{ }^{\circ} \mathrm{C}$ até peso constante.

As variáveis foram submetidas à análise de variância, conforme delineamento, ajustando-se os dados para obtenção da curva doseresposta por regressão polinomial.

\section{RESULTADOS E DISCUSSÃO}

\section{Pós-emergência inicial}

As plantas apresentaram, em todas as espécies estudadas, sintomas de intoxicação mais intensos e massa seca reduzida principalmente a partir da aplicação de $375 \mathrm{~L} \mathrm{ha}^{-1}$ de óleo fúsel, aos 7 e 30 DAA (Figuras 1 e 2). As diferenças entre espécies podem estar relacionadas, segundo Costa et al. (2006), às características morfológicas e anatômicas intrínsecas a cada uma delas. As diferenças entre as doses são inerentes à maior quantidade do óleo fúsel utilizada.

Os sintomas visuais de intoxicação observados nas plantas daninhas caracterizaramse pelo rápido murchamento, seguido de amarelecimento e secamento das plantas; resultados semelhantes também foram observados por Azania et al. (2008).

Em todas as espécies, observou-se maior intoxicação na parte aérea das plantas, gradualmente com o aumento das doses do óleo fúsel; na pós-emergência inicial, a máxima intoxicação ocorreu nas doses de 375 e $500 \mathrm{~L} \mathrm{ha}^{-1}$, aos 7 e 30 DAT (Figura 1). Essa constatação permite comentar que uma comunidade infestante constituída pelas 

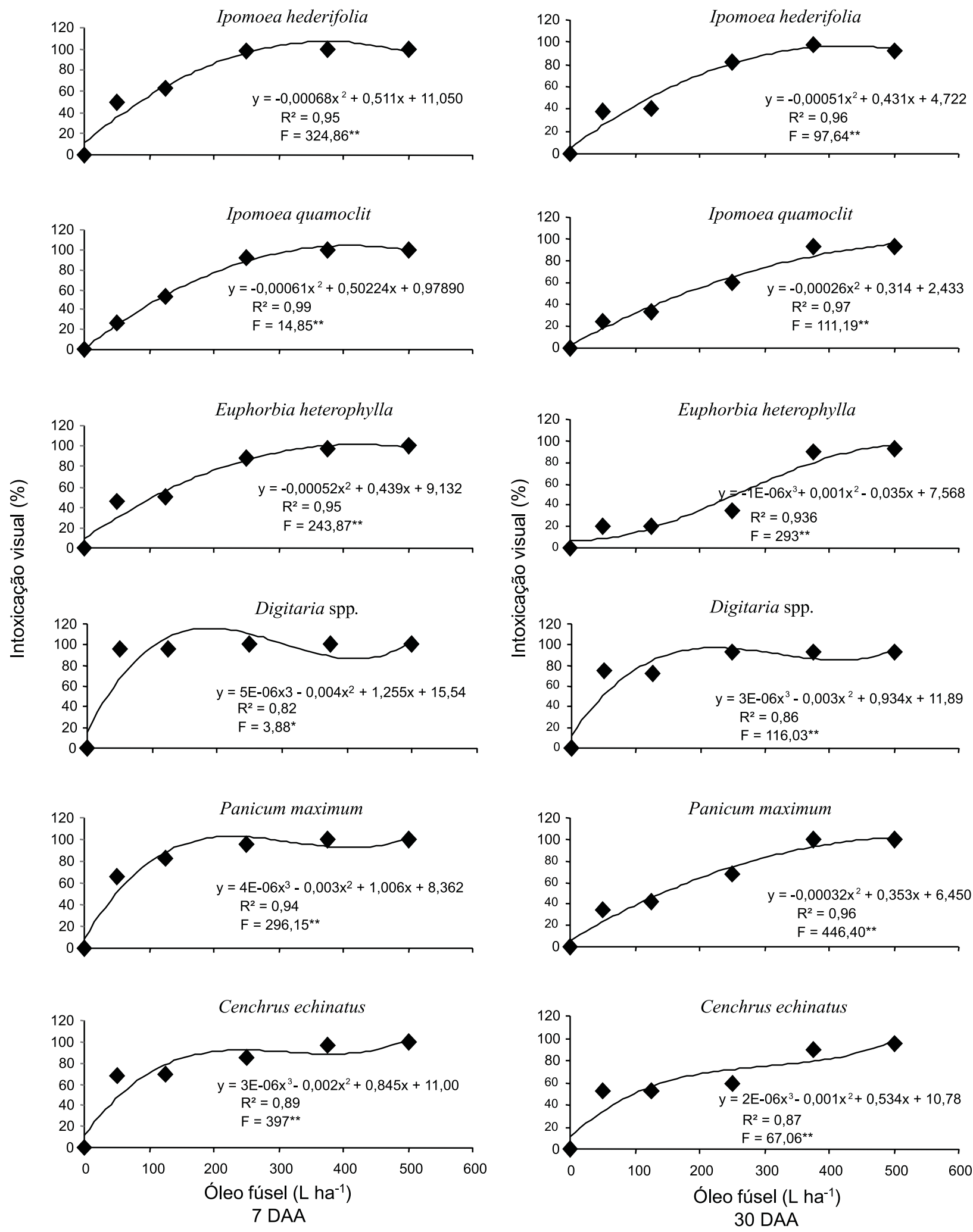

Figura 1 - Notas de intoxicação visual (\%) observadas na parte aérea das plantas daninhas aos 7 e 30 dias após aplicação (DAA) de doses de óleo fúsel em pós-emergência inicial. Instituto Agronômico, 2009. 

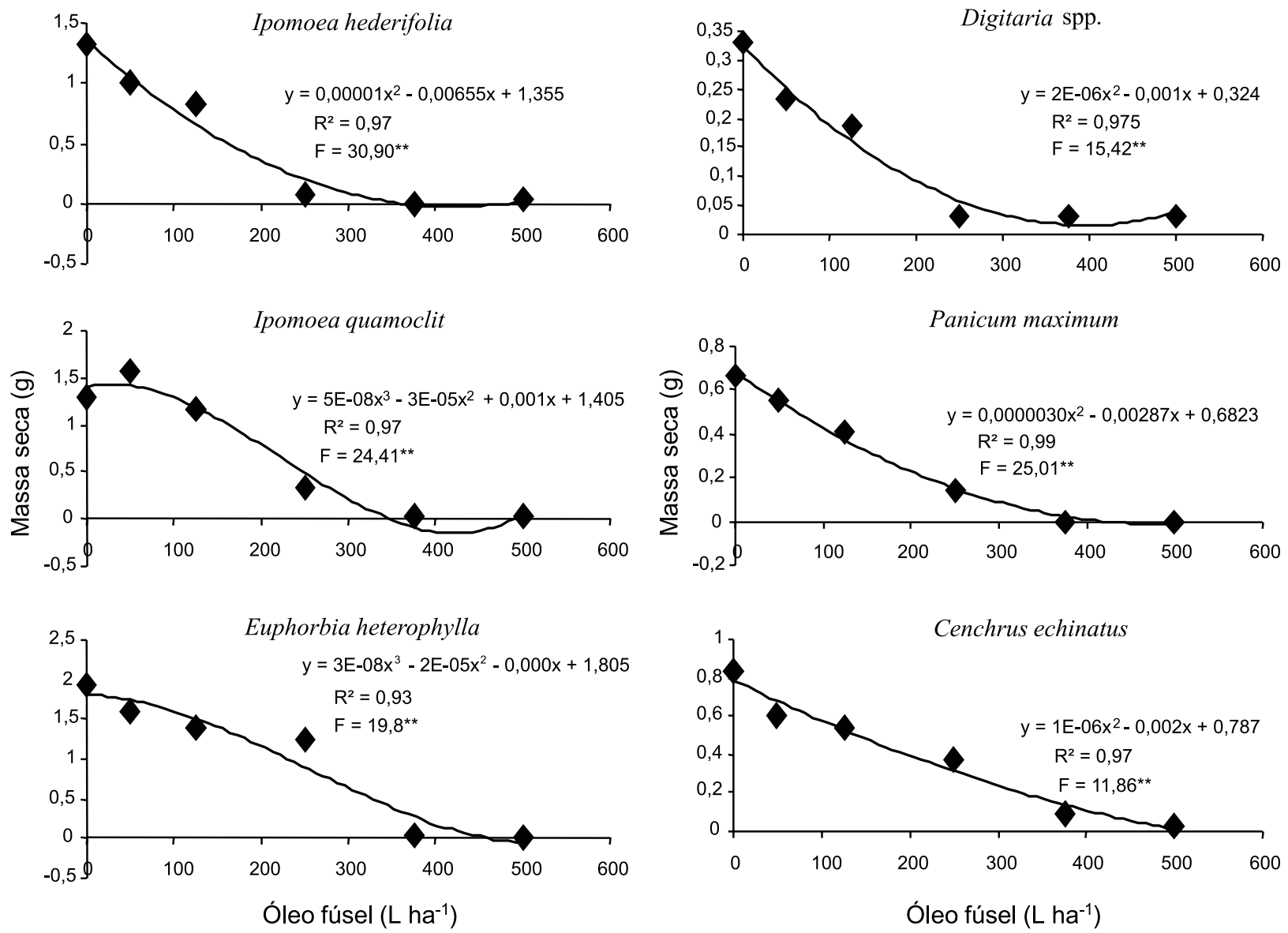

Figura 2 - Massa seca (g) da parte aérea de diferentes espécies de plantas daninhas aos 30 dias após aplicação (DAA) de doses de óleo fúsel em pós-emergência inicial. Instituto Agronômico, 2009.

plantas daninhas em estudo seria mais bem controlada com doses do subproduto a partir dos $375 \mathrm{~L} \mathrm{ha}^{-1}$.

A variável massa seca foi inversamente proporcional aos sintomas de intoxicação, pois os valores decresceram com o aumento das doses do óleo fúsel e, consequentemente, as doses mais elevadas resultaram em ausência de acúmulo de massa seca (Figura 2).

$\mathrm{Na}$ condição de pós-emergência inicial, Digitaria spp. foi a mais suscetivel e E. heterophylla a mais tolerante entre as espécies estudadas; as demais foram medianamente suscetiveis quanto às variáveis avaliadas.

Para Digitaria spp., aos 7 e 30 DAA, mesmo as doses mais baixas do óleo fúsel causaram sintomas de intoxicação mais pronunciados (Figura 1), levando-as ao total secamento
(Figura 2). Osipe et al. (2009) observaram 86\% de controle para Digitaria insularis no sistema de plantio direto, com o uso de óleo fúsel a 220 e $440 \mathrm{~L} \mathrm{ha}^{-1}$ aos 21 DAA.

Entretanto, não foi possivel determinar a espécie de Digitaria controlada pelo óleo fúsel, pelo fato de o fornecedor das sementes não ter realizado a identificação enquanto ainda estavam na planta. Segundo Dias et al. (2007), a identificação é facilitada ao observar as estruturas, como gluma, tricomas e lema, presentes nas espiguetas. Após limpeza e manuseio das sementes, a identificação ficou prejudicada, não sendo possivel afirmar qual espécie de Digitaria foi utilizada.

E. heterophylla foi a espécie mais tolerante ao uso do óleo fúsel porque aos 30 DAA (Figura 1) apresentou injúrias leves a moderadas para as doses de 50, 125 e $250 \mathrm{~L} \mathrm{ha}^{-1}$ $(20,20$ e $35 \%)$ e severas para as doses de 375 e 
$500 \mathrm{~L} \mathrm{ha}^{-1}$ (90 e 92,5\%). Nas doses até $250 \mathrm{~L} \mathrm{ha}^{-1}$ observou-se também maior acúmulo de massa seca (Figura 2). Segundo Wilson (1981), E. heterophylla é de dificil controle e considerada prejudicial às culturas, devido à sua capacidade de sobrevivência em condições adversas; também de acordo com Trezzi et al. (2006), apresenta elevada produção e dispersão de sementes.

Entretanto, ao considerar todas as espécies quanto aos sintomas visuais de intoxicação, observaram-se diferenças entre as plantas daninhas mono e dicotiledôneas aos 7 DAA. Quanto às monocotiledôneas, 50, 125 e $250 \mathrm{~L} \mathrm{ha}^{-1}$ do óleo fúsel foram suficientes para causar sintomas visuais mais pronunciados acima de $60 \%$, ao passo que nas dicotiledôneas os sintomas de intoxicação foram superiores a $60 \%$ somente a partir da aplicação de $250 \mathrm{~L} \mathrm{ha}^{-1}$ (Figura 1). Na sequência, aos 30 DAA observou-se pouca recuperação das plantas quanto aos sintomas visuais de intoxicação (Figura 1), refletindo no menor acúmulo de massa seca nas monocotiledôneas e maior nas dicotiledôneas (Figura 2).

Essas diferenças são explicadas pelas características morfológicas e anatômicas intrínsecas a cada espécie (Costa et al., 2006), pela diversidade morfológica da epiderme foliar, pelo tipo de cera epicuticular, tricomas e estômatos que influenciam na deposição dos herbicidas sobre a superficie foliar (Hess \& Falk, 1990), além da espessura e composição da camada cuticular, que determinam a facilidade de absorção dos herbicidas (Silva et al., 2002).

\section{Pós-emergência tardia}

As plantas de todas as espécies estudadas também apresentaram sintomas de intoxicação mais pronunciados e massa seca reduzida apenas nas doses de 375 e $500 \mathrm{~L} \mathrm{ha}^{-1}$ de óleo fúsel, aos 7 e 30 DAA (Figuras 3 e 4). A diferença entre espécies pode estar relacionada às características morfológicas e anatômicas intrínsecas à espécie (Hess \& Falk, 1990; Costa et al., 2006), e as diferenças entre as doses são inerentes à maior quantidade do óleo fúsel utilizada.

E. heterophylla foi suscetivel, as espécies da família Poaceae foram moderadamente tolerantes, e as da família Convolvulaceae, tolerantes ao óleo fúsel, considerando os sintomas de intoxicação observados nas plantas (7 e 30 DAA) e o acúmulo de massa seca até os 30 DAA (Figuras 3 e 4).

A moderada sensibilidade das plantas da família Poaceae pode ser observada aos 30 DAT, pela menor intensidade dos sintomas de intoxicação (Figura 3) e pelo acúmulo de massa seca (Figura 4) em relação àqueles de E. heterophylla, excetuando-se C. echinatus e $P$. maximum nas maiores doses. A tolerância das plantas da familia Convolvulaceae também pode ser observada aos 30 DAA (Figura 3) pelas injúrias leves a moderadas até mesmo na máxima dose utilizada (500 $\left.\mathrm{L} \mathrm{ha}^{-1}\right)$, sem reduções no acúmulo de massa seca, exceto na dose máxima.

Para E. heterophylla, os sintomas de intoxicação foram gradualmente maiores com as doses aos 7 DAA, atingindo $100 \%$ na maior dose. Na avaliação aos 30 DAA (Figura 3) atribuíram-se às plantas $60 \%$ de sintomas de intoxicação na menor dose do óleo fúsel (50 L ha ${ }^{-1}$ ), entre 80 e $90 \%$ nas doses intermediárias (125 e $\left.250 \mathrm{~L} \mathrm{ha}^{-1}\right)$ e $100 \%$ nas maiores doses (375 e $500 \mathrm{~L} \mathrm{ha}^{-1}$ ). A redução no acúmulo de massa seca a partir de $125 \mathrm{~L} \mathrm{ha}^{-1}$ de óleo fúsel (Figura 4) evidencia que a espécie foi mais prejudicada pela aplicação do subproduto em pós-emergência tardia.

Essa espécie comportou-se como tolerante ao óleo fúsel aplicado em pós-emergência inicial, mas suscetível quando aplicado em pósemergência tardia. A diferença entre a suscetibilidade e a tolerância possivelmente se deva à espessura e composição da camada cuticular (Silva et al., 2002), que pouco alterou com o crescimento da planta no período entre as aplicações em pós-emergência inicial e tardia.

Às espécies da família Poaceae, aos 7 DAA, foram atribuídas notas de sintomas de intoxicação inferiores a 40\% nas menores doses do óleo fúsel (50 e $125 \mathrm{~L} \mathrm{ha}^{-1}$ ) e entre 40 e $80 \%$ nas demais doses (Figura 3), sendo os maiores valores considerados em campo como de efeito moderado a severo.

Na avaliação aos 30 DAA, Digitaria spp. e Cenchrus echinatus não mostraram recuperação ou maiores prejuízos à parte aérea porque 

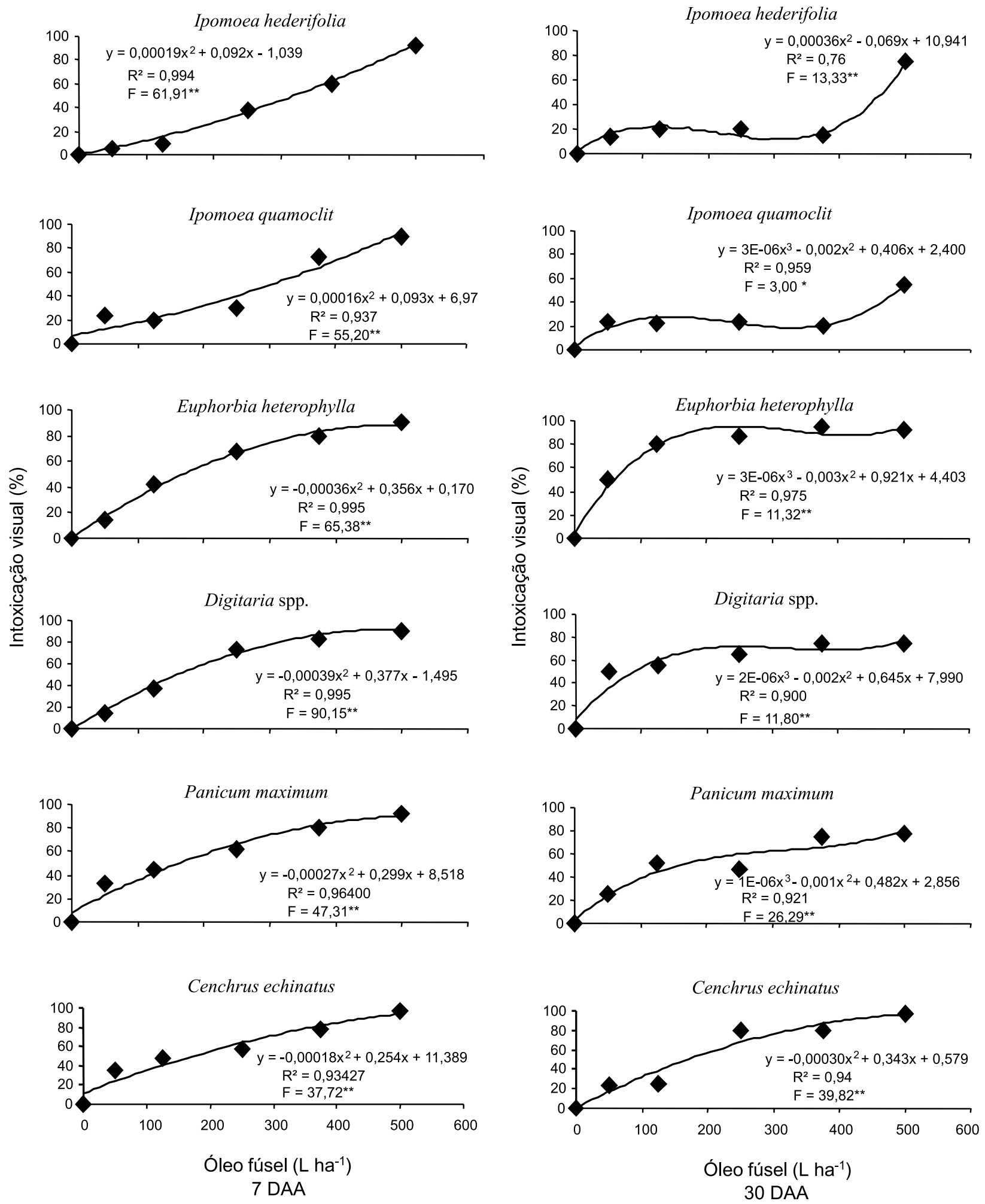

Figura 3 - Notas de intoxicação visual (\%) observadas na parte aérea das plantas daninhas aos 7 e 30 dias após aplicação (DAA) de doses de óleo fúsel em pós-emergência tardia. Instituto Agronômico, 2009. 

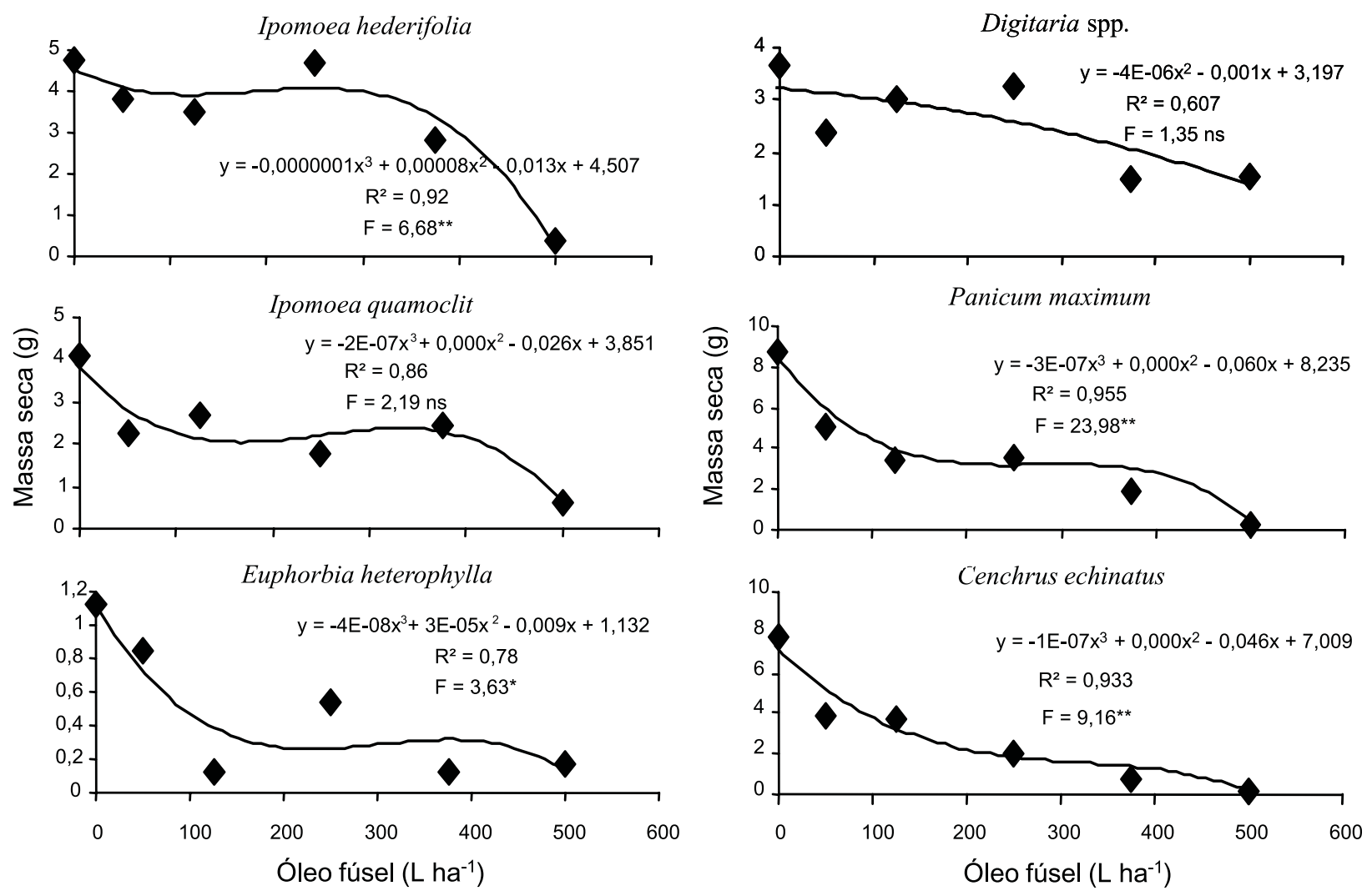

Figura 4 - Massa seca (g) da parte aérea de diferentes espécies de plantas daninhas aos 30 dias após aplicação (DAA) de doses de óleo fúsel em pós-emergência tardia. Instituto Agronômico, 2009.

as notas atribuídas aos sintomas de intoxicação também não foram maiores que $80 \%$ nas doses de 250, 375 e $500 \mathrm{~L} \mathrm{ha}^{-1}$ de óleo fúsel; contudo, $P$. maximum apresentou leve recuperação ao serem atribuídas notas pouco inferiores a $80 \%$ nas maiores doses (Figura 3).

A redução no acúmulo de massa seca nas plantas dessas espécies nos tratamentos com as maiores doses do óleo fúsel evidencia a morte das plantas (Figura 4). Para Digitaria spp., a diferença na massa seca acumulada pelas plantas nas diferentes doses não foi significativa estatisticamente. As plantas de Digitaria possuem crescimento lento (Machado et al., 2006), indicando que o acúmulo de massa seca na testemunha foi pequeno, assim como nas demais doses de aplicação do subproduto, e resultando na não significância dos dados de acordo com o delineamento proposto.

A tolerância das plantas da família Convolvulaceae pode ser constatada ao se observar a recuperação das plantas quanto a sintomas de intoxicação na avaliação dos 7 e 30 DAA: na maior dose e para ambas as espécies foi atribuída nota próxima a $100 \%$ para os sintomas de intoxicação aos 7 DAA e inferior a $80 \%$ aos 30 DAA (Figura 3).

Entretanto, o acúmulo de massa seca apenas foi ausente nas plantas de $I$. hederifolia tratadas com a maior dose do subproduto, evidenciando a morte delas (Figura 4). Para I. quamoclit, o acúmulo de massa seca também ficou prejudicado devido ao pouco desenvolvimento das plantas no tratamento testemunha, que não diferenciou o suficiente para atingir a significância estatística.

As espécies estudadas foram suscetiveis apenas com a utilização de $500 \mathrm{~L} \mathrm{ha}^{-1}$ de óleo fúsel aplicado na pós-emergência inicial ou tardia das plantas. A espécie de Digitaria spp. foi suscetivel; E. heterophylla, tolerante; e as demais, moderadamente tolerantes às doses de óleo fúsel aplicadas em pós-emergência inicial. A espécie de E. heterophylla 
foi suscetivel; Digitaria spp., C. echinatus e $P$. maximum moderadamente tolerantes; e I. hederifolia e I. quamoclit, tolerantes às doses de óleo fúsel aplicadas em pós-emergência tardia.

\section{LITERATURA CITADA}

AZANIA, A. A. P. M. et al. Emergência e desenvolvimento de guanxuma (Sida rhombifolia), capim-braquiária (Brachiaria decumbens) e cana-de-açúcar (Saccharum spp.) influenciados por subprodutos da destilação do álcool. Planta Daninha, v. 22, n. 3 , p. $331-336,2004$

AZANIA, A. A. P. M. et al. Germinação de sementes de Sida rhombifolia e Brachiaria decumbens influenciada por vinhaça, flegmaça e óleo fúsel. Planta Daninha, v. 21, n. 3, p. 443-449, 2003.

AZANIA, A. A. P. M. et al. Aplicação de óleo fúsel isolado e em mistura com glifosato na pós-emergência tardia de plantas daninhas. Planta Daninha, v. 26, n. 1, p. 231-236, 2008.

COSTA, N. V.; RODELLA, R. A.; MARTINS, D. Diferenciação de espécies daninhas aquáticas pela análise multivariada de caracteres estruturais foliares.

Planta Daninha, v. 24, n. 1, p. 13-20, 2006.

DIAS, A. C. R. et al. Problemática da ocorrência de diferentes espécies de capim-colchão (Digitaria spp.) na cultura da cana-de-açúcar. Planta Daninha, v. 25, n.2, p. 489-499, 2007.

HESS, F. D.; FALK, R. H. Herbicide deposition on leaf surfaces. Weed Sci., v. 38, n. 3, p. 280-288, 1990.
MACHADO, A. F. L. et al. Análise de crescimento de Digitaria insularis. Planta Daninha, v. 24, n. 4, p. 641-647, 2006.

OLIVEIRA, J. R. Óleo fúsel: mais rentável que o ethanol. Disponível em: < http://ethanolbrasil.blogspot.com/2007/02/ leo-fsel-mais-rentvel-que-o-ethanol.html> . Acesso em: 17 mar.2009

OSIPE, R. et al. Avaliação da eficiência de diferentes doses de óleo fúsel no controle de Digitaria insularis (capim-amargoso) e Commelina benghalensis (trapoeraba). R. Bras. Agroecol., v. 4, n. 2, p. 1042-1045, 2009.

PÉREZ, E. R.; CARDOSO, D. R.; FRANCO, D. W. Análise dos álcoois, ésteres e compostos carbonílicos em amostras de óleo fúsel. Química Nova, v. 24, n. 1, p. 10-12, 2001.

PIZZO, I. V. et al. Seletividade e eficácia de controle de plantas daninhas pela associação entre óleo fúsel e herbicidas em cana-de-açúcar. Planta Daninha, v. 28, n. 2, p. 347-357, 2010 .

SILVA, A. A. et al. Biologia e controle de plantas daninhas. Brasília: ABEAS, 2002. 189 p.

TREZZI, M. M. et al. Efeitos de resíduos da parte aérea de sorgo, milho e aveia na emergência e no desenvolvimento de plântulas de leiteiro (Euphorbia heterophylla) resistentes a inibidores da ALS. Planta Daninha, v. 24, n. 3, p. 443-450, 2006.

WILSON, A. K. Euphorbia heterophylla: a review of distribution, importance and control. Trop. Pest. Manag., v. 27, n. 1, p. $32-38,1981$. 